\title{
Seismic Vibration Control of Structures Using Superelastic Shape Memory Alloys
}

\author{
Hongnan Li and Hui Qian \\ Dalian University of Technology, Zhengzhou University
}

China

\section{Introduction}

Structural vibration control has been approved effective design strategy for enhancing structural performance against earthquake and mitigating seismic response. Passive vibration control is a promising technology which has been widely used in earthquake engineering due to its simple configuration, low cost, easy maintenance and reliable run without power support. However, current technologies present some limitations, such as problems related to aging and durability, residual displacement, substitution after strong events, among others. Recently, the increasing research and development of smart materials and controlling devices open up a new area for seismic vibration control of structural engineering, providing a basic platform for the design and exploration of new generation high-performance structural systems.

Shape memory alloys (SMAs) are a class of novel smart materials that possess unique properties, including shape memory effect, superelasticity effect, extraordinary fatigue resistance, and high corrosion resistance and damping characteristics, which make them perfect candidates for applications in seismic resistant design and retrofit of structures.

A significant number of research studies have been conducted in an effort to use SMAs for applications in seismic resistant design and retrofit of structures in the past decade. The results of the previous works show there is promise for SMAs in earthquake engineering. However, significant research is still needed, particularly as SMAs strands are planted into the concrete structures. The damping property and self-recentering capacity of the SMAs-based intelligent RC structure need to be further studied. In addition, to design some new types of passive seismic devices which possess not only energy dissipation and recentering capabilities but also simple configuration for easy installation in the practical engineering is still actual issue currently. Moreover, at present, there is little available data on the optimization of their size and position of the SMAs dampers in a structure as the economic cost is considered.

This chapter presents some applications of shape memory alloys in seismic resistant design. Main contents are included as follows: 


\section{Vibration Control of Concrete Structures Reinforced With Superelastic Shape Memory Alloy}

\subsection{Self-rehabilitation property of intelligent concrete beams reinforced with superelastic SMA strands}

Cracks can seriously affect the durability of reinforced concert structures. SMA has the properties of shape memory effect, super-elasticity, and good corrosion resistance, which can change the properties of the concrete structures (Choi et al, 2008; Maji et al, 1998; Song et al, 2006). In this section, we focus on the self-rehabilitation property of intelligent concrete structures reinforced with superelastic SMA strands.

\subsubsection{Specimens}

Two concrete beams were fabricated and their dimensions and reinforcement arrangements are shown in Fig. 1. The reinforcements of specimen RC are steel wires with a diameter of $2.2 \mathrm{~mm}$. The reinforcements of specimen A are super-elastic SMA strands, which are composed of seven single wires with a diameter of $0.75 \mathrm{~mm}$. The mechanical properties of SMA strands and steel wires can be found in the Ref. (Li et al, 2006).

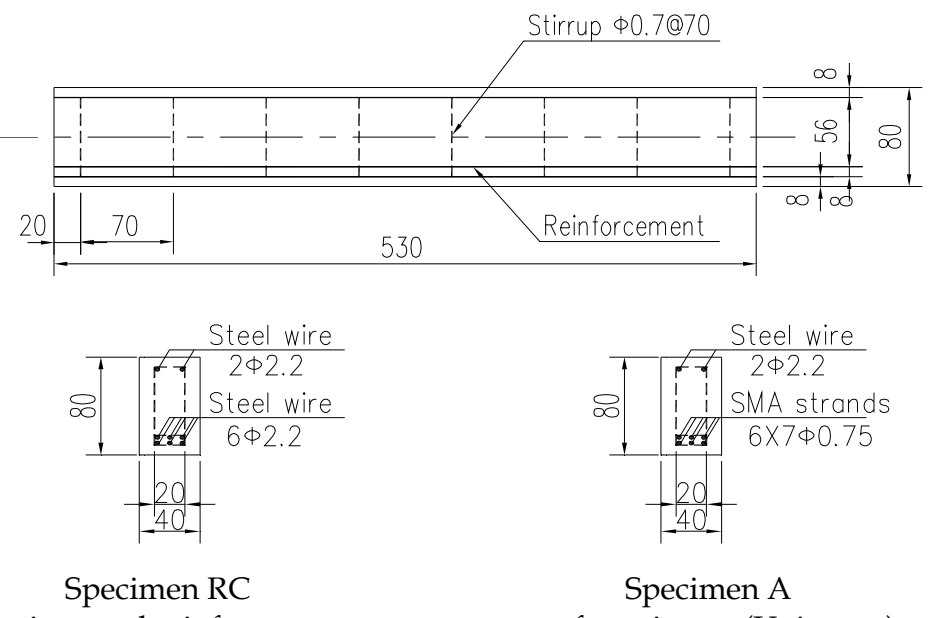

Fig. 1. Dimensions and reinforcement arrangements of specimens (Unit: $\mathrm{mm}$ )

\subsubsection{Three-point bending test}

In this experiment, the three-point bending tests were conducted on the specimens. The load is measured by a load cell in the test machine, the deflection at mid-span of the specimens is measured by a micrometer gauge, and the crack width is measured by an extensometer. The loading process is controlled by the displacement at mid-span and the loading rate is $0.2 \mathrm{~mm} / \mathrm{min}$; the maximal displacement is set at $10 \mathrm{~mm}$. 


\subsubsection{Experimental results}

The load-deflection curves of specimens are shown in Fig. 2. Specimen RC (Fig. 2(a)) shows obvious yield behavior after the 2nd loading cycle. The load-deflection curve of specimen A (Fig. 2(b)) shows hysteresis characteristics. After cracks are generated, the deformation of the SMA strands is very small, and the stress also small because its Young's modulus is just $1 / 5$ of that of steel, and thus the bearing capability decreases immediately. With the increasing of the loading cycle numbers, the bearing capability of specimen A increase greatly; its bearing capability can reach to $6617.40 \mathrm{~N}$ at the last cycle.

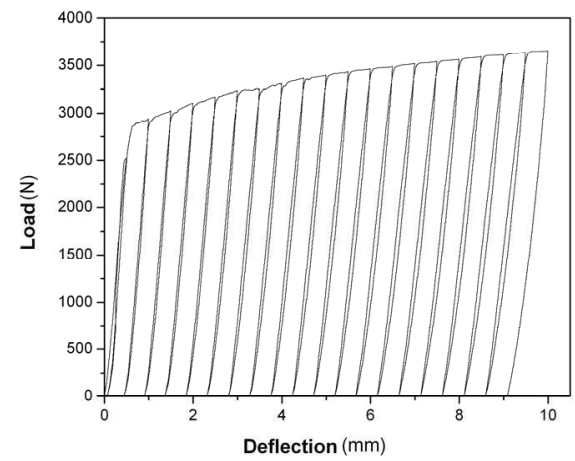

(a) Specimen RC

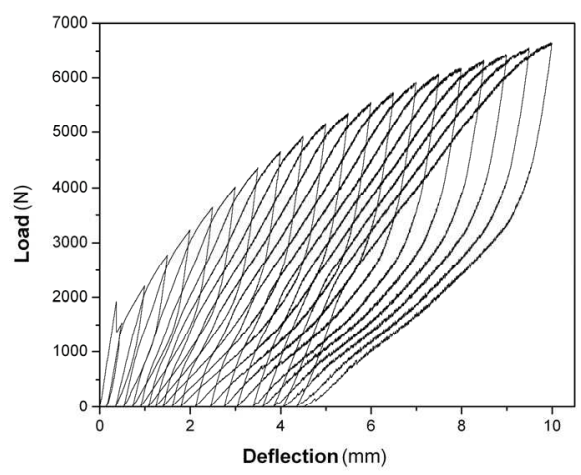

(b) Specimen A

Fig. 2. Load-deflection curves of specimens

To illustrate the effects of super-elastic SMA strands in controlling the crack width, Fig. 3 shows the relationship between the residual crack width and the No. of loading cycles. The residual crack width of specimen RC and specimen A both increase with the increase of the loading cycles. Due to the superelasticity and the cementing bond between SMA strands and concrete, the crack width of specimen A is smaller than that of specimen RC.

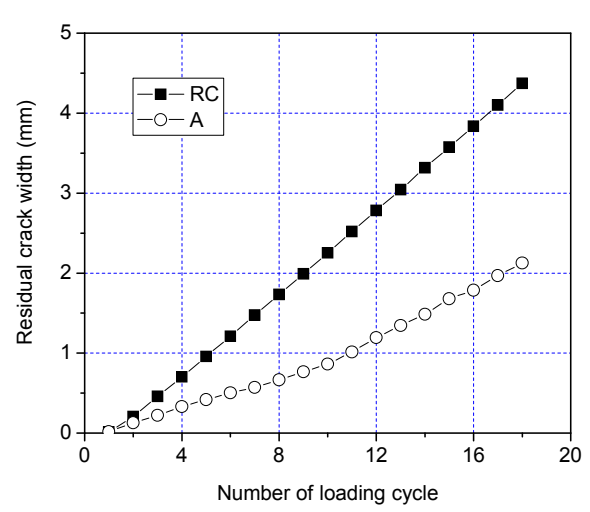

Fig. 3. Relationship between residual crack and number of loading cycles

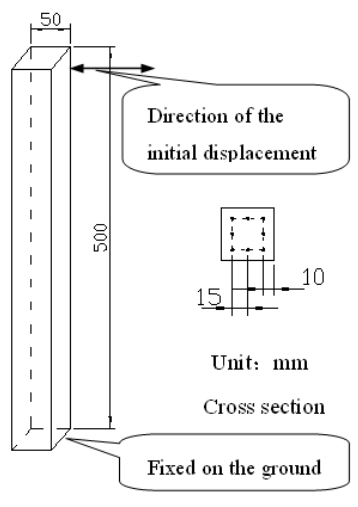

Fig. 4. Sketch of concrete column and details of its cross section 


\subsection{The influence of superelastic SMAs on the damping ratio of concrete columns}

In the past several years, studies have shown the feasibility of using shape memory alloys for passive and active damping applications. The SMA energy dissipation devices have been proposed for bridges and buildings (Dolce et al, 2000; Wilde et al, 2000). Although studies have shown the feasibility of using SMAs as external energy dissipation devices, little has been done in using SMAs as inner energy dissipation devices to change the properties of concrete structures or structural members under seismic loadings or wind loadings in civil engineering. In this section, the reinforcements of the concrete columns are replaced by superelastic SMA wires to investigate the influence of SMAs as internal energy dissipation devices on the damping ratio of concrete columns.

\subsubsection{Specimens}

For comparison, the three kinds of concrete columns that were designed are as shown in Fig. 4. One is reinforced with eight steel wires (specimen S8), the other is reinforced with eight superelastic SMA wires (specimen A8), the third one is reinforced with eight martensitic SMA wires (specimen M), respectively. The mechanical properties of the steel wires and the SMA wires can be found in the Ref. (Cui et al, 2009).

\subsubsection{Test instruments and method}

To obtain the damping ratio of the specimens, the initial displacement method is utilized to measure the vibration curves of each specimen. The direction of the initial displacement is shown in Fig. 4. During the test, AR-5F acceleration transducer is used to measure the acceleration response of the top of the columns. All the test data are collected by a real-time data acquisition system named DSPS. For specimen M, martensitic SMA wires were strained up to $4 \%$ and connected with each other in series. During the test, the martensitic SMA wires were heated with a large current of $40 \mathrm{~A}$.

\subsubsection{Test results}

The normalized free vibration curves of the columns are shown in Fig. 5. The damping ratios of the specimens are listed in Table 1. From Fig. 5, it can be seen that after being electrified, the vibration curve of specimen $M$ attenuates very fast, its damping ratio is almost the same with that of specimen $S$. The results demonstrate that the initial phase of SMA wires has great influence on the damping ratio of the structural members. Thus, the superelastic SMAs can be taken as an inter energy dissipation device to control the vibration of the structures.

\subsection{Seismic response mitigation and the self-recentering capability of concrete frame with SMA strands}

To investigate the capability of the self-damping and self-recentering of superelastic SMA reinforced concrete structure (SMA-structure), a two-layer eccentric structure was designed in this section as shown in Fig. 6, where, CK is the center of stiffness, and CM is the center of mass. The eccentricity is $e_{x}=0.647 \mathrm{~m}$ and $e_{y}=0.0 \mathrm{~m}$. For reinforced concrete structure without SMAs (RC-structure), the rebar in the beams and columns are all steel; for the 
SMA-structure, the rebar in beams are still steel, while the rebar in columns are superelastic SMA wires.

The seismic responses of structures are analyzed by using the finite element analysis program ANSYS. The SOLID185 of ANSYS is used to model the beams and columns of the frame structure. The MASS21 of ANSYS is used to model the weight of the structure.

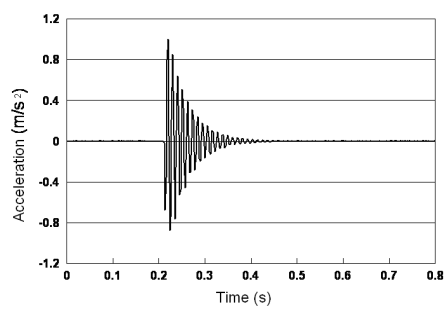

(a) Specimen $\mathrm{S}$

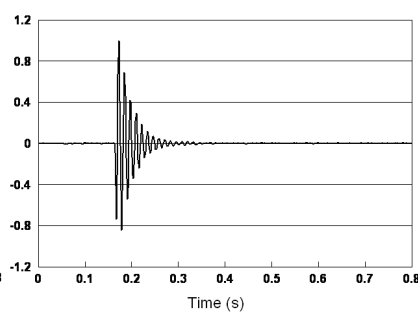

(b) Specimen A8

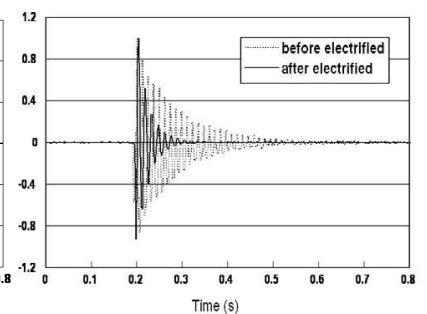

(c) Specimen $\mathrm{M}$

Fig. 5. Free vibration curves of specimens

Table 1. Damping Ratios of Specimens

\begin{tabular}{ccccc}
\hline \multirow{2}{*}{ Specimen } & \multirow{2}{*}{ S } & A8 & \multicolumn{2}{c}{$\mathrm{M}$} \\
\cline { 4 - 6 } & & & (before electrified) & (after electrified) \\
\hline Damping ratio (\%) & 4.18 & 6.22 & 2.08 & 6.30 \\
\hline
\end{tabular}

The seismic responses of the superelastic SMA reinforcedstructure and the RC-structure are analyzed in the time domain. The Ninghe, El Centro and Qian'an earthquake records are selected to be input to the structure as excitations, representing different site conditions. The peak accelerations of earthquake records are scaled to $0.4 \mathrm{~g}\left(\mathrm{~g}=9.8 \mathrm{~m} / \mathrm{s}^{2}\right)$. The structural response of SMA-structure is expressed by $R_{S M A}$. Also, the response of RC-structure is expressed by $R_{B C}$. The response reduction ratio of the structure is defined as

$$
\eta=\frac{R_{R C}-R_{S M A}}{R_{R C}} \times 100 \%
$$



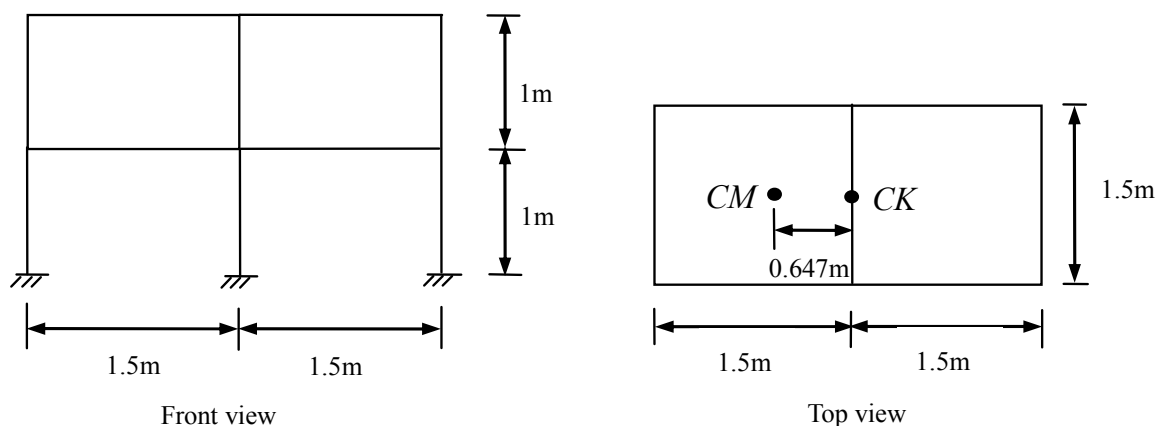

Fig. 6. Plan of the structure

The maximum displacements of the structures and the response reduction ratios are computed for three earthquake records. The results are listed from Table 2 to Table 4 , where, $\eta_{d x}, \eta_{d y}$ and $\eta_{\theta}$ are the reduction ratio in $x, y$ and torsion direction. It can be seen from the tables that the responses of SMA-structure in each degree of freedom are almost less than those of RC-structure. However, the reduction ratios are different for the different earthquake records. The displacement time history curves of top story are shown from Fig. 7 to Fig. 9 for El Centro earthquake. It can be seen from these figures that the structural response are reduced in the whole time history under the influence of the SMA wires.

In order to investigate the self-restoring capability of SMA-structure, the position variation situation of the structure center under El Centro earthquake is shown in Fig. 10. It is obvious that superelastic SMA reinforced structure always move around the initial position. This phenomenon fully demonstrates the excellent self-restoring capability of SMA-structures compared to RC-structures.

Table 2. Maximum displacements of the structures (Qian'an)

\begin{tabular}{cccccccccc}
\hline & \multicolumn{3}{c}{$X(\mathrm{~mm})$} & \multicolumn{3}{c}{$Y(\mathrm{~mm})$} & \multicolumn{3}{c}{$\theta$} \\
\cline { 2 - 10 } & SMA & RC & $\eta_{d x}(\%)$ & SMA & RC & $\eta_{d y}(\%)$ & SMA & RC & $\eta_{\theta}(\%)$ \\
\hline 1 & 2.9 & 3.2 & 16.75 & 3.1 & 3.8 & 19.07 & 2.36 & 2.89 & 18.37 \\
2 & 5.0 & 4.8 & -3.16 & 5.9 & 5.9 & 0.79 & 4.47 & 4.41 & -1.25 \\
\hline
\end{tabular}

Table 3. Maximum displacements of the structures (El Centro)

\begin{tabular}{cccccccccc}
\hline & \multicolumn{3}{c}{$X(\mathrm{~mm})$} & \multicolumn{3}{c}{$Y(\mathrm{~mm})$} & \multicolumn{3}{c}{$\theta\left(\times 10^{-3} \mathrm{rad}\right)$} \\
\cline { 2 - 11 } & SMA & $\mathrm{RC}$ & $\eta_{d x}(\%)$ & SMA & RC & $\eta_{d y}(\%)$ & SMA & RC & $\eta_{\theta}(\%)$ \\
\hline 1 & 4.7 & 8.0 & 41.49 & 5.8 & 10.0 & 42.28 & 4.31 & 7.46 & 42.20 \\
2 & 7.7 & 9.1 & 15.93 & 9.6 & 11.5 & 16.13 & 7.17 & 8.57 & 16.35 \\
\hline
\end{tabular}


Table 4. Maximum displacements of the structures (Ninghe)

\begin{tabular}{cccccccccc}
\hline & \multicolumn{3}{c}{$X(\mathrm{~mm})$} & \multicolumn{3}{c}{$Y(\mathrm{~mm})$} & \multicolumn{3}{c}{$\theta$} \\
\cline { 2 - 10 } & SMA & RC & $\eta_{d x}(\%)$ & SMA & RC & $\eta_{d y}(\%)$ & SMA & RC & $\eta_{\theta}(\%)$ \\
\hline 1 & 4.3 & 29.9 & 85.74 & 5.3 & 37.2 & 85.74 & 3.97 & 27.99 & 85.81 \\
2 & 6.2 & 31.1 & 80.16 & 8.0 & 39.5 & 79.76 & 5.90 & 29.53 & 80.02 \\
\hline
\end{tabular}

\section{Innovative Superelastic SMAs-based Re-centering Damping Device for Structural Vibration Control}

\subsection{Innovative Superelastic SMAs-based Re-centering Damping Device}

In this study, innovative hybrid SMA friction device (HSMAFD) (Li et al, 2008) as energy dissipation device was considered. HSMAFD consists of recentering device based on pre-tensioned superelastic NiTi wires and friction device (FD), as shown in Fig. 11. The superelastic NiTi wires mainly perform a function of recentering due to large restoring

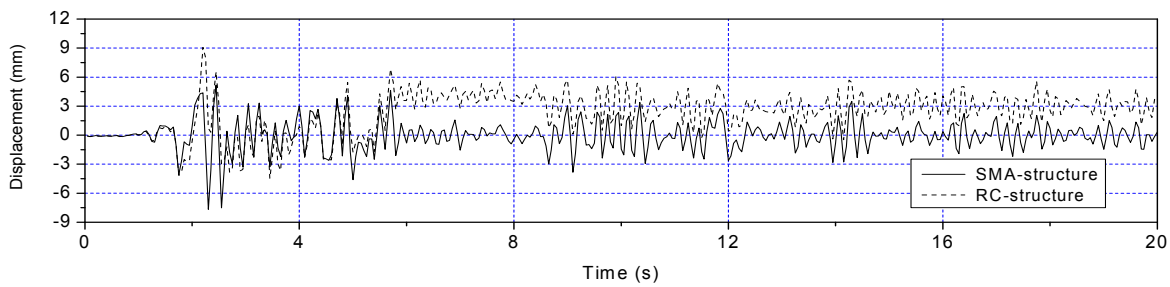

Fig. 7. Time history of the displacement in $x$ direction of top story (El Centro)

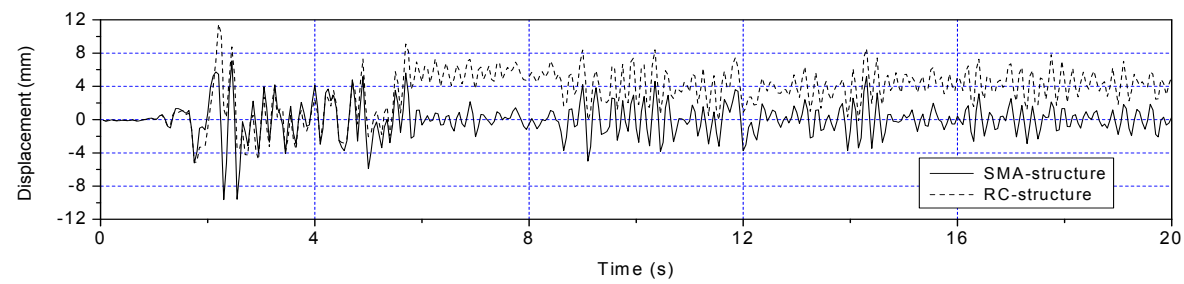

Fig. 8. Time history of the displacement in y direction of top story (El Centro)

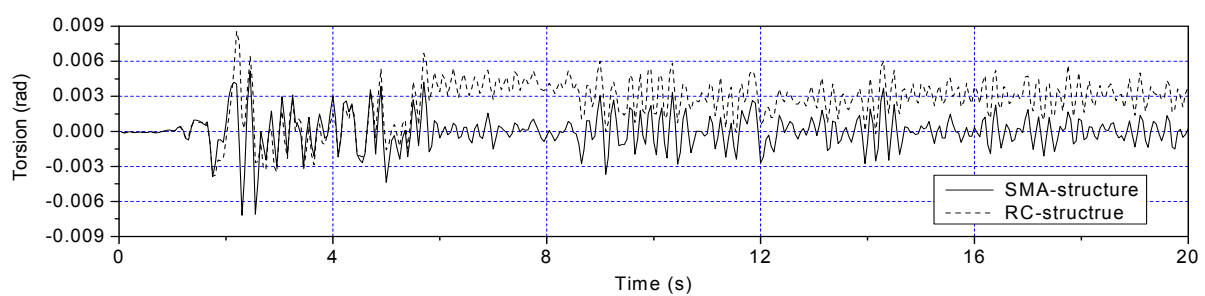

Fig. 9. Time history of the torsional displacement of top story (El Centro) 

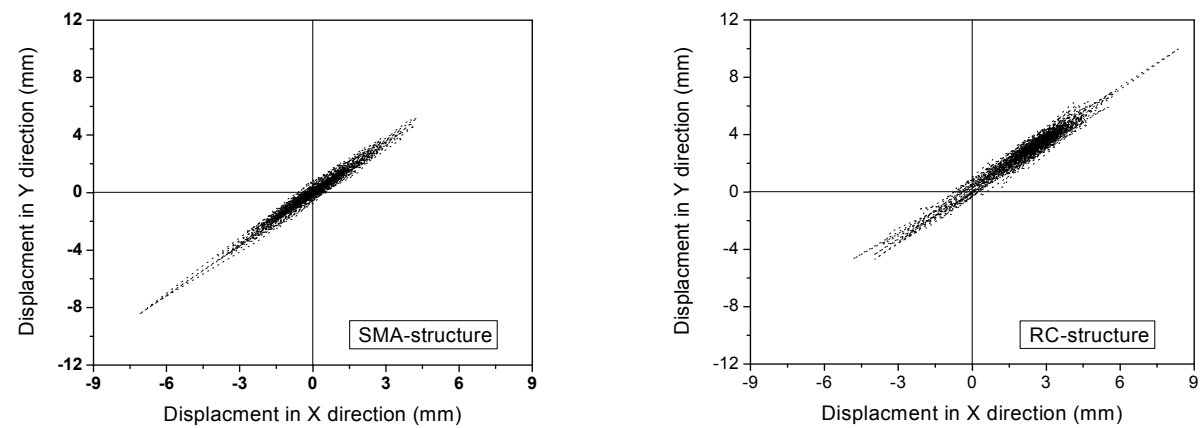

Fig. 10. Position change of structures under El Centro earthquake (0.4g)

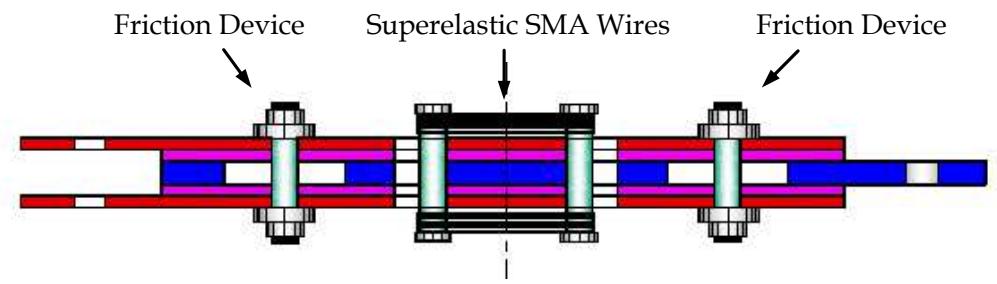

Fig. 11. Scheme diagram of a HSMAFD
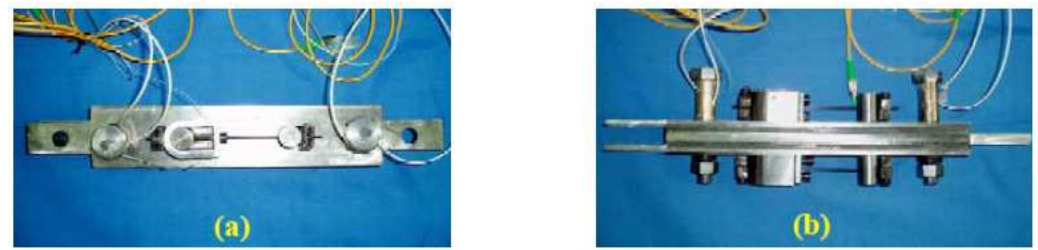

Fig. 12. Photos of HSMAFD

force, as well as additional energy dissipation owing to their hysteretic damping property. The friction devices are utilized to dissipate most seismic energy by relative sliding between the friction plants impacted by high strength bolts. By properly combining the number and the pre-tensioning level of the superelastic SMA wires and the friction force, the device exhibits supplemental recentering capacity and energy dissipating feature, which can be exploited to reduce structural seismic response and return the building to the initial position after earthquakes. Fig. 12 presents a HSMAFD model fabricated based on the design.

Fig. 13 shows hysteretic behavior of a HSMAFD under sinusoidal cyclic displacements of increasing amplitudes with loading frequency of $0.05 \mathrm{~Hz}, 0.1 \mathrm{~Hz}, 1.0 \mathrm{~Hz}$ and $2.0 \mathrm{~Hz}$, respectively. As we can see, satisfying hysteretic loops, including both recentring and the energy dissipating features, were obtained under various conditions. With the increase of the displacement amplitude, the energy dissipation per cycle increases almost linearly, 
while the secant stiffness and the equivalent damping decrease. Moreover, the performance is not highly sensitive to frequencies of loading in the range of which earthquake engineering concerns.

\subsection{Shaking Table Tests}

\subsubsection{Shaking table}

The experimental tests were carried out on the earthquake simulator shaking table of the State Key Laboratory of Coastal and Offshore Engineering in Dalian University of Technology. It included a $3 \mathrm{~m} \times 4 \mathrm{~m}$ steel platform, with three degree of freedom, driven by servo-hydraulic actuators which were numerically controlled by a MTS analogue electronic control system. The shaking table has about 10 tons payload capacity with frequency band of $0.1 \sim 50 \mathrm{~Hz}$.

\subsubsection{Structural model}

The structural model in the tests is a $1 / 4$ scaled three-story steel frame. Its overall dimension is $1.5 \times 1.5 \mathrm{~m}$ in plane and $2.4 \mathrm{~m}$ in elevation. All the columns in the model have constant cross section $(30 \mathrm{~mm} \times 30 \mathrm{~mm} \times 3 \mathrm{~mm}$ angle iron). Similarly, all the beams have the same cross section $(60 \mathrm{~mm} \times 40 \mathrm{~mm} \times 3 \mathrm{~mm}$ rectangle iron). The main geometrical characteristics of the steel frame model are shown in Fig. 14. The yield stress and Young's modulus of the material are $215 \mathrm{MPa}$ and 206GPa, respectively. Masses added to the structure are $300.6 \mathrm{~kg}$ for the first floor, $300 \mathrm{~kg}$ for the second floor and $318.5 \mathrm{~kg}$ for the third floor.

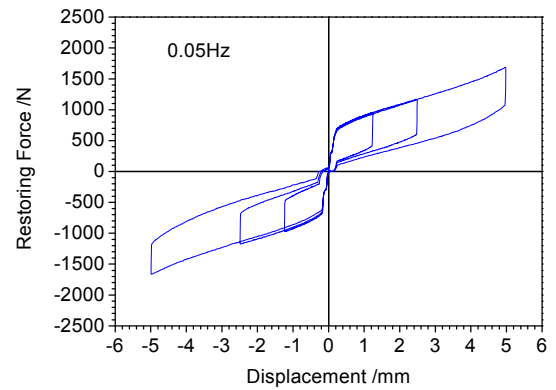

(a-1)

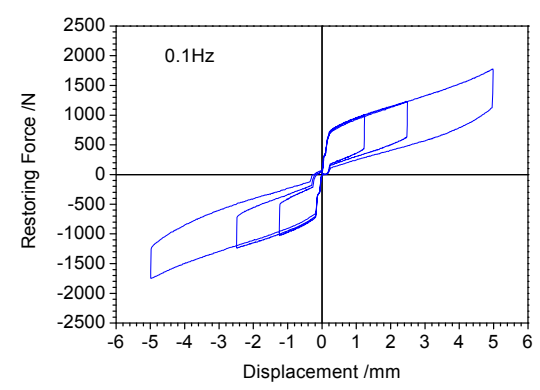

$(\mathrm{a}-2)$

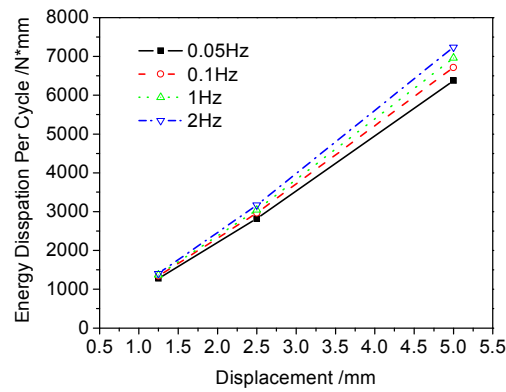

$(\mathrm{b}-1)$

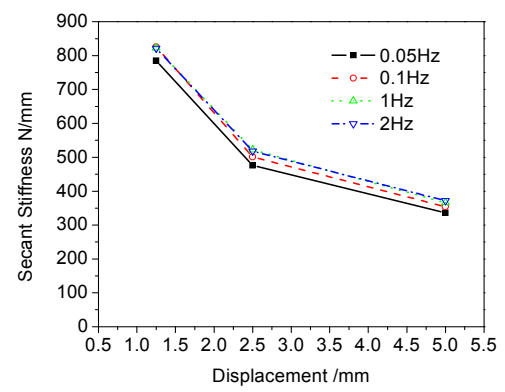

$(\mathrm{b}-2)$ 


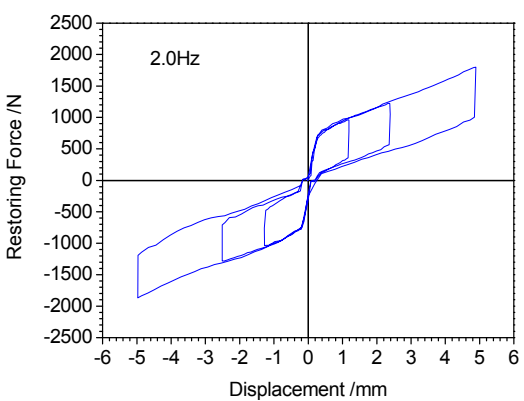

(a-3)

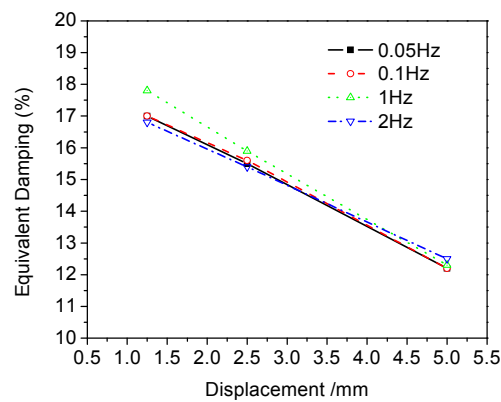

(b-3)

Fig. 13. Hysteretic behaviour of HSMAFD under various loading frequency and displacement amplitudes: (a) Force-displacement curves; and (b) Mechanical quantities.

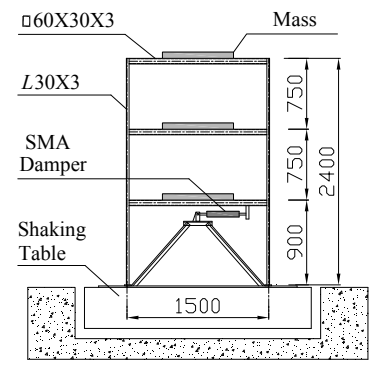

(a)

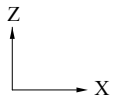

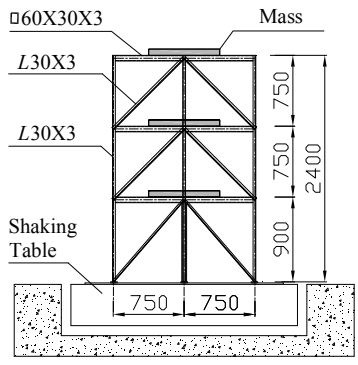

(b)

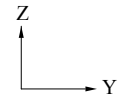

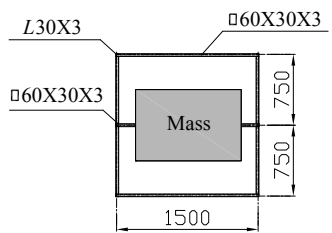

(c)

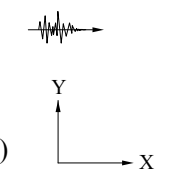

Fig. 14. Geometrical characteristics of the steel frame model (unit: $\mathrm{mm}$ ):

(a) X direction elevation; (b) Y direction elevation; and (c) typical floor plan.

\subsubsection{Earthquake historical records}

In the tests, the flowing three earthquake historical records were selected: (i) El Centro. The N-S component recorded at the Imperial Valley Irrigation District substation in El Centro, California, during the Imperial Valley, California earthquake of May 18, 1940; (ii) Taft. The S69E component recorded at Taft Lincoln School Tunnel, Kern County, California earthquake of August 31, 1976; (iii) Tianjin. The N-S component recorded at the Tianjin hospital, Ninghe, Tangshan aftershock of November 15, 1976. The absolute peak acceleration of the earthquake records are adjusted to $0.15 \mathrm{~g}$. Additionally, the equally-spaced intervals of El Centro, Taft and Tianjin are 0.01s, 0.01s and 0.005s, respectively. Additionally, random white noise tests were conducted to identify the fundamental frequency of vibration and assess the damage suffered by the structure subjected to the seismic records. 


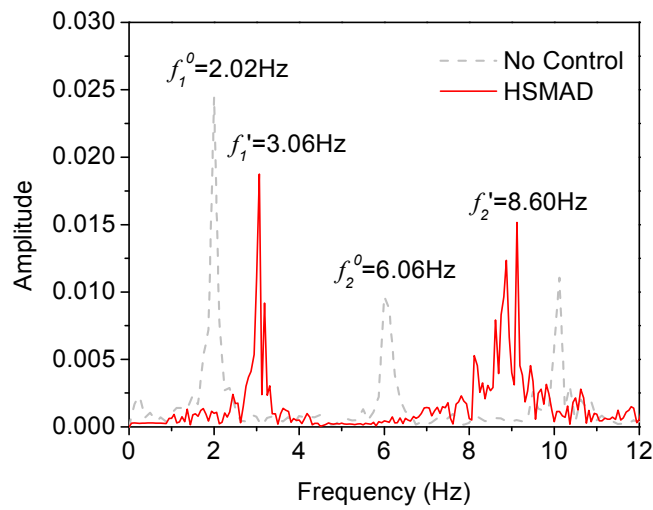

Fig. 15. Frequency spectrum of the free and controlled structures

\subsubsection{Shaking table tests results}

Fig. 15 shows the frequency spectrum of the structure with and without damping device. As can be seen, the fundamental frequency of the structure increases from $2.02 \mathrm{~Hz}$ to $3.06 \mathrm{~Hz}$, up more than $50 \%$, after HSMAFD was installed, which indicates that the energy dissipation system provides supplemental stiffness into the original structure.

Fig. 16 shows the profiles of maximum interstorey drifts for the free and controlled structures under different earthquakes with $0.15 \mathrm{~g}$ PGA. As seen from the figure, interstorey drifts of the building have been non-identically reduced. Especially, compared with the two upper floors, the first floor has a more significant effect, decreasing by $69.1 \%$ for El Centro, by $65.5 \%$ for Taft and by $77.1 \%$ for Tianjin, respectively. This is because the damping device was only installed in the first floor of the building.

Fig. 17 shows the profiles of maximum absolute displacements relative to the table for the free and controlled structures under different earthquakes with $0.15 \mathrm{~g}$ PGA. As can be seen, the maximum absolute displacements relative to the table of the top floor of the building decrease by $61.0 \%$ for El Centro, $45.7 \%$ for Taft and $65.6 \%$ for Tianjin, respectively.

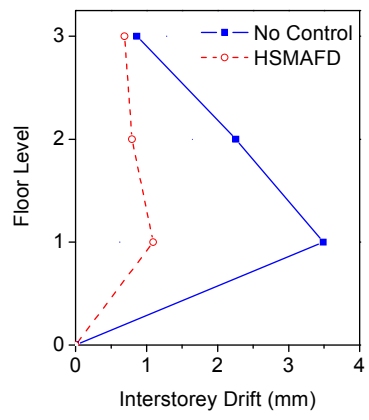

(a) El Centro

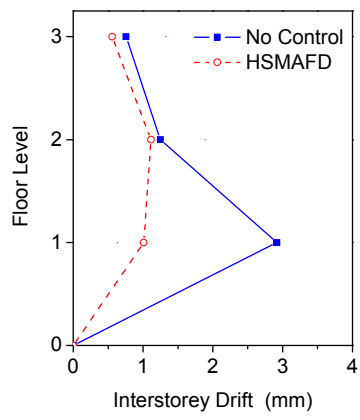

(b) Taft

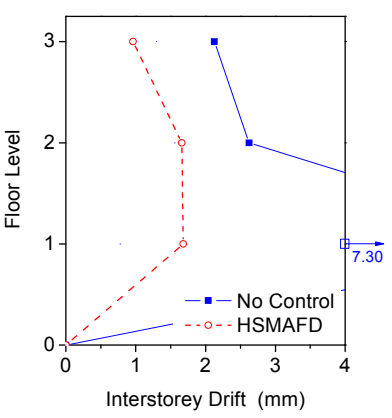

(c) Tianjin

Fig. 16. Profiles of maximum interstorey drifts for the free and controlled structures 


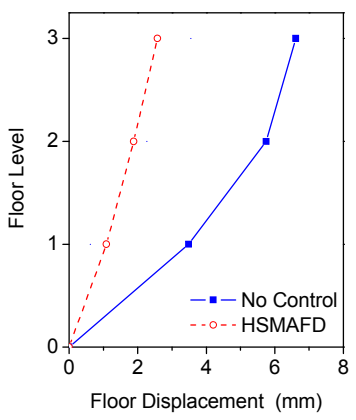

(a) El Centro

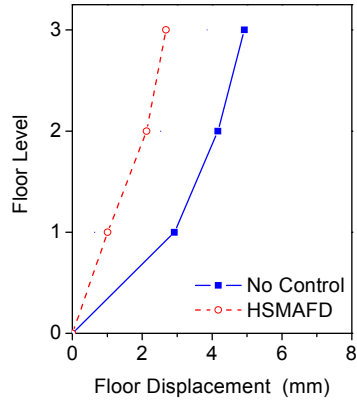

(b) Taft

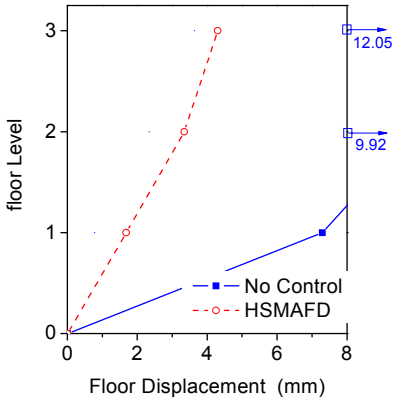

(c) Tianjin

Fig. 17. Profiles of maximum absolute displacements for the free and controlled structures
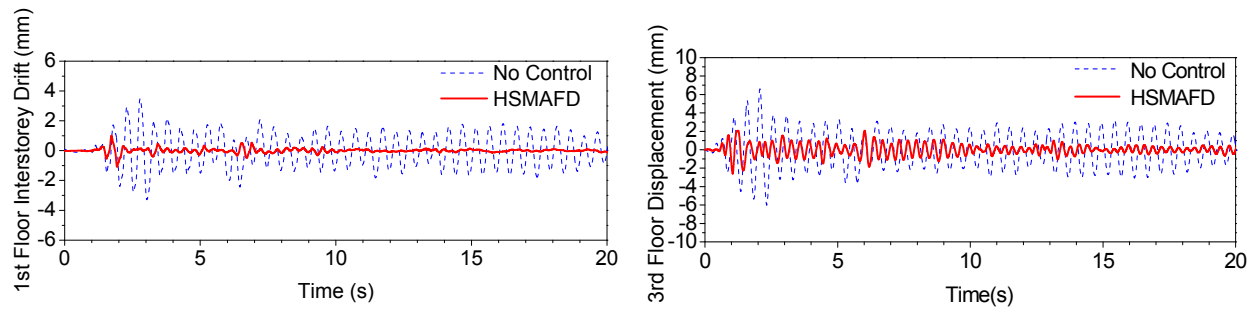

(a) El Centro record (PGA=0.15g).
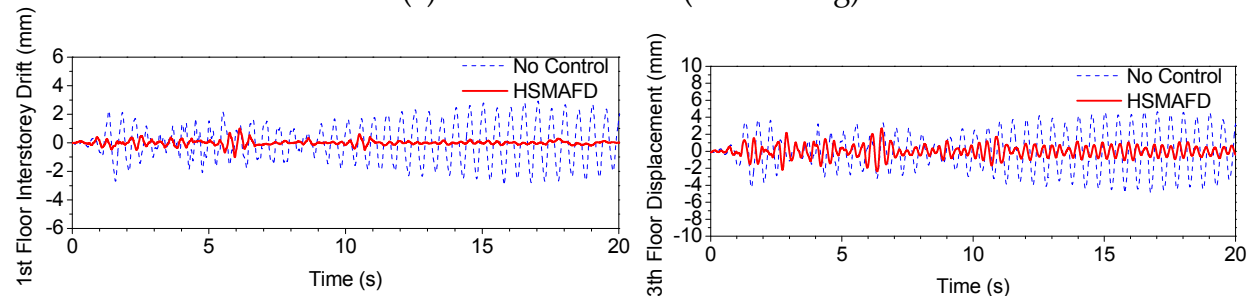

(b) Taft record (PGA $=0.15 \mathrm{~g})$.
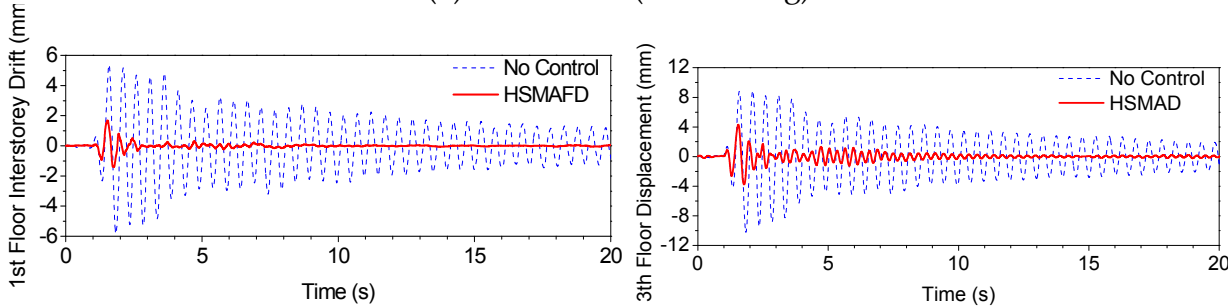

(c) Tianjin record (PGA $=0.15 \mathrm{~g})$.

Fig. 18. Time history of interstorey drift of the 1st floor and absolute displacement of the 3rd floor under different seismic records 


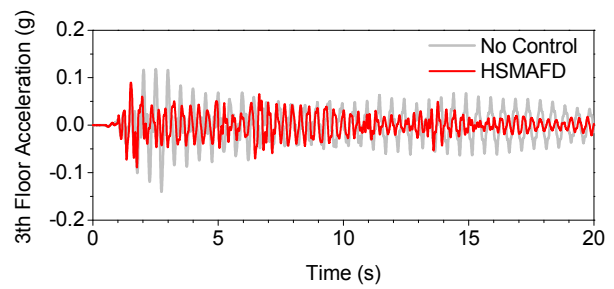

(a) El Centro, PGA=0.15g

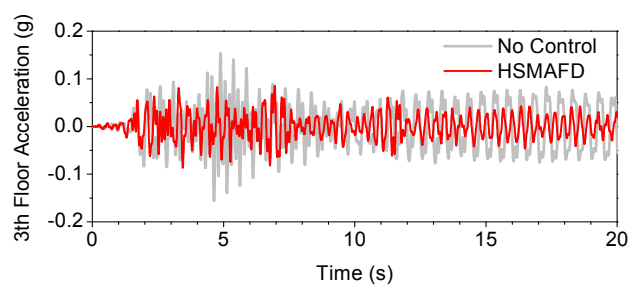

(b) Taft, PGA $=0.15 \mathrm{~g}$

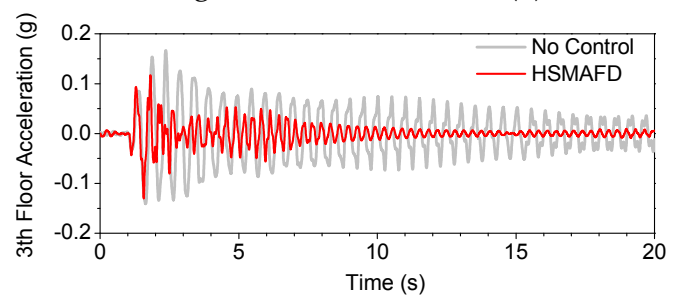

(c) Tianjin, PGA $=0.15 \mathrm{~g}$

Fig. 19. Time history of acceleration of the 3th floor under different seismic records

Fig. 18 shows the time history of the 1st floor interstorey drifts and the 3rd floor absolute displacement of structure with and without energy dissipation system under different seismic records. In the figures, the blue dashed lines and the red solid lines represent the seismic response of the free and controlled structures, respectively. As we can seen, the seismic response of the structure have been significant reduced by the SMA damper.

Fig. 19 shows the time history of the 3rd floor acceleration of the free and controlled structure. As can be seen, the accelerations of the 3rd floor have been reduced, but no significant control effects are found because the energy dissipation system adds supplemental stiffness into the original structure.

\section{SMA Damper Installation Optimization for Three-dimensional Structural Response Control with Improved Multi-objective Genetic Algorithm}

\subsection{Introduction}

In order to use damping devices economically, the optimization of their size and position in a structure is an important issue. Researchers have suggested different practical schemes for optimal configuration of dampers, such as sequential search algorithms (Zhang et al, 1992; Shukla et al, 1999), a steepest directions search algorithm (Takewaki 1997), a worst-out-best-in and exhaustive single point substitution methods (Agrawal, et al 2000) and genetic algorithms (GAs) (Singh et al, 2002; Wongprasert et al, 2004). However, these studies are restricted to two-dimensional plane frame structures. Very few practical building structures have no eccentric axes of rotation and inertia, and can be modeled as plane structures. Moreover, a three-dimensional (3-D) structure with the eccentric location of axes of rotation and inertia has coupled lateral and torsional responses under the action of earthquake, even when excited unidirectionally. Furthermore, seismic ground motions are generally not unidirectional phenomena (Ahlawat et al,2003). Thus, these optimal schemes 
cannot be used for the majority of practical buildings. Some efforts to address optimal damper systems for 3-D structures have been made. Wu and Ou (1997) studied the optimal placement procedures for determining the visco-elastic dampers in asymmetrical structures to minimize the coupling effects of translation-torsion. Ahlawat and Ramaswamy (2003) designed an optimal tuned mass damper system in order to control the acceleration, displacement and torsion responses of a 3-D building. Although these designs serve well, they are carried out based on certain assumptions, i.e. the size of dampers is not included in the optimization problem but determined in advance. In reality, like the position of dampers, the size of dampers also has a significant effect on the control of structural response (Li et al, 2001). The determination of the size of dampers may be affected by many factors, for instance the total weight of structures, total cost of control, and control demands. If the size and position of dampers and the structural performance are considered simultaneously, the problem may become more complex and be characterized as a multi-objective optimization problem (MOP).

In view of mathematics, multi-objective optimization offers the potential tool to consider various and mutually conflicting requirements inherent in a problem so that it admits a family of perfect solutions rather than a single one. The GAs have successfully been applied to the MOPs. Most multi-objective GAs involve in assigning a single fitness value to each individual, weather via a weighted-sum approach that combines all objectives into a single fitness function, or some forms of ranking scheme that assigns better fitness values to individuals based on their non-dominance (Crossley et al, 1999). However, for the former, choosing the proper weights induces difficulties, because the likely output would normally be affected by the dominant objective only (Zheng et al, 2004); and for the latter, the population rank is a really complicated process for practical applications. Crossley et al (1999) presented the two-branch tournament GA that evaluates individuals competing on one of two objectives, i.e. one branch of the tournament selects individuals according to the first objective, the other branch for the second objective. This selection mechanism seems more convenient for practical use, but it fails to work well in a problem with more objectives because more branches corresponding to more objectives are required. For example, Ahlawat and Ramaswamy (2003) employed three branches instead of two to handle three objective functions, which resulted in an increasingly complicated selection and more computational effort. In addition, for a constrained optimization, penalty function methods have been successfully used in the GAs to treat single-objective constrained optimization by adding a penalty term to the fitness of an infeasible individual to make its fitness never attain that of a feasible one, but the approaches cannot be extended to a MOP, because the search goal of the MOP is a region rather than an point, and the fitness of a point has no direct connection with its objective functions(Cheng and Li, 1997).

In this section, the problem of optimizing a SMA damper system when incorporated into a 3-D structure is given. To solve a MOP, a constrained multi-objective GA is first presented by integrating an improved selection operator based on the two/three-branch tournament GA and a Pareto-based penalty function method. The improved algorithm is then followed by verification through two mathematical benchmark problems. Finally, the improved GA is used to deal with the optimal size and position of SMA dampers for a six-story torsionally 
coupled building subjected to earthquake in order to achieve a desired level of reduction in both translational and torsional responses at minimum cost.

\subsection{Improved Constrained Multi-objective GA}

\subsubsection{Selection operator}

The improved approach is constructed by evaluating individuals based on their non-dominance in one run rather than reproducing individuals on each objective in each branch as the two/three-branch tournament GA. To do this, a pot and parent pools are set in advance. The entire population of a current generation is placed in the pot. Two individuals, $X_{1}$ and $X_{2}$, are randomly selected without replacement from the pot and compete on their dominance: If $\phi_{i}\left(X_{1}\right)>\phi_{i}\left(X_{2}\right)$ for all $i \in\{1,2, \cdots, n\}$, the individual $X_{2}$ dominates the individual $X_{1}, X_{2}$ is copied to the parent pool twice and $X_{1}$ is discarded, or vice versa; otherwise, the two individuals are equally dominant and each one is copied to the parent pool once. This continues until the pot is empty and the parent pool is full. Then, the individuals in the parent pool are again randomly selected without replacement, two at a time, and mated in the crossover operation to form two individuals. The mutation operation is subsequently performed on certain individuals, with a certain probability of mutation. These offspring eventually become the next generation of designs.

In the algorithm just described, there are certain guarantees about the selection process even though individuals are randomly chosen from the pot. In each run, individuals are selected without replacement, so that all individuals will have one opportunity to compete on their non-dominance, the better performing individual will always prevail against its competition, and the most copies an individual can have in the parent pool is two. These features provide a slight selection pressure toward better individuals, but still maintain the diversity needed to represent a spectrum of individuals across the Pareto optimal set (Crossley et al 1999). An example of bi-objective optimization problem is shown in Fig. 20. Four design variables are defined as $X_{1}, X_{2}, X_{3}$ and $X_{4}$ with the corresponding objective values included in the brackets, and the underlined variables represent the selected individuals. In the improved selection, all non-dominated individuals, $X_{1}, X_{2}$ and $X_{3}$ are always reproduced once or twice. However, the two-branch GA sometimes sees that the non-dominated individual $X_{1}$ is discarded and the dominated individual $X_{4}$ is selected twice. This example shows that the improved selection operator may be superior to the two-branch tournament in searching the Pareto optima. 


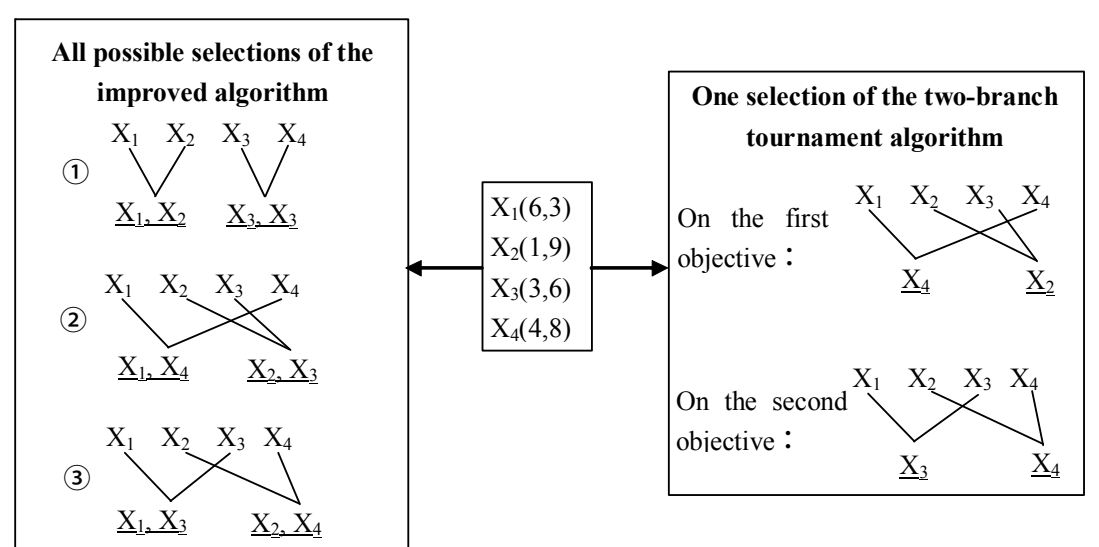

Fig. 20. Selected solutions of two-branch Tournament algorithm and its improved version

In addition, the improved selection operator takes less computational effort due to the evaluation of individuals in each generation being completed in one run, regardless of the objective dimension.

\subsubsection{Pareto-based penalty function}

The GAs can be applied to a constrained optimization problem by using penalty function methods to transform a constrained problem into an unconstrained one. In the selection operator above described, an individual is evaluated according to its non-dominance. Thus, the penalty functions should reflect an individual's non-dominance in a population correctly According to the definition of the Pareto optima, the non-dominance of an individual is defined by its status (feasible or infeasible), distance from the Pareto optimal set, and position in an infeasible zone (Cheng and Li 1997). Thereby, four rules should be followed as: (1) a feasible individual is superior to an infeasible one; (2) the closer an individual is to the feasible zone, the more superior it is; and (3) the closer an individual is to the Pareto optimal set, the more superior it is; (4) the second rule supersedes the third because an infeasible solution is unacceptable in a constrained optimization problem. The Pareto-based penalty function method yields:

$$
\phi_{i}^{\prime}(X)=\left\{\begin{array}{c}
\phi_{i}(X), r_{\mathrm{c}}(X)=0, \text { for feasible individuals } \\
C+r_{\mathrm{c}}(X)+\frac{\phi_{i}(X)}{C}, r_{\mathrm{c}}(X)>0, \text { for infeasible individuals }
\end{array},(i \in\{1,2, \cdots n\}),\right.
$$

where, $C$ means a positive constant with very large value and $r_{c}$ denotes the penalty term which ranks the infeasible individual according to its violated amount for constraint $R_{c}$, where

$$
R_{\mathrm{c}}(X)=\sum_{j=1}^{p} g_{j}^{+}(X), g_{j}^{+}(X)=\left\{\begin{array}{c}
0, g_{j}(X) \leq 0 \\
g_{j}(X), \quad g_{j}(X)>0
\end{array}\right.
$$


If $R_{c}$ equals 0 , then $r_{c}$ equals 0 ; while $R_{c}$ increases, $r_{c}$ increases as $1,2, \cdots, \phi_{i}(X) / C$ is the sub-penalty term that has a value within a very small range, for example $[-0.1,0.1]$.

Eq. (2) and Eq. (3) are consistent with the foregoing four rules. First, the improved selection operator guarantees that the third rule does. The new objective functions $\left\{\phi_{1}^{\prime}, \phi_{2}^{\prime}, \cdots, \phi_{n}^{\prime}\right\}$ can indicate whether an individual is feasible $\left(r_{\mathrm{c}}=0\right)$ or infeasible $\left(r_{\mathrm{c}}>0\right)$, and can also ensure that a feasible individual gets lower objective values than an infeasible one due to the introduction of $C$. For an infeasible individual, the same value of $r_{\mathrm{c}}$ is used for all objective functions, which can guarantee the same penalty to all objectives. For example, design variables, $X_{1}$ and $X_{2}$, are two infeasible individuals: if $X_{1}$ is closer to the feasible zone than $X_{2}, R_{\mathrm{c}}\left(X_{1}\right)<R_{\mathrm{c}}\left(X_{2}\right)$, then $r_{\mathrm{c}}\left(X_{1}\right)<r_{\mathrm{c}}\left(X_{2}\right)$, so $\phi_{i}\left(X_{1}\right)<\phi_{i}\left(X_{2}\right)$ for all $i \in\{1,2, \cdots, n\}$, so $X_{1}$ dominate $X_{2}$. The sub-penalty term plays its role only when infeasible individuals are equidistant from the feasible region, due to its very small value. Seeing the just above example, if $X_{1}$ and $X_{2}$ are equidistant from the feasible region, $r_{\mathrm{c}}\left(X_{1}\right)=r_{\mathrm{c}}\left(X_{2}\right)$, then if $\phi_{i}\left(X_{1}\right) / C<\phi_{i}\left(X_{2}\right) / C$ for all $i \in\{1,2, \cdots, n\}, X_{1}$ dominates $X_{2}$, else $X_{1}$ and $X_{2}$ are equally dominant.

\subsubsection{Pareto-set filter}

Reproduction of a new generation cannot assure that the best traits of the parents are always inherited by their offspring. Some of these traits may never appear in future phases of evolution due to the limited population size (Cheng and Li 1997). To avoid missing optimal individuals, a Pareto-set filter is employed. At each generation, the non-dominated individuals are put into a filter. When new individuals are added, all individuals in the filter are subjected to a non-dominated check (filtering process) and the dominated individuals are discarded (Cheng and Li 1997). Thus, only non-dominated individuals are stored in the filter.

The filter size can be set to equal population size or any other reasonable size. When the desired storage capacity is exceeded, the individuals at a minimun distance relative to other individuals are removed to maintain an even design distribution in the filter (Cheng and $\mathrm{Li}$ 1997). The distance between individuals, $X_{1}$ and $X_{2}$, can be calculated as follows (Huang et al., 2007)

$$
d=\sqrt{\sum_{i=1}^{n}\left(\frac{\phi_{i}\left(X_{1}\right)-\phi_{i}\left(X_{2}\right)}{\phi_{i, \max }-\phi_{i, \min }}\right)^{2}}
$$

where $\phi_{i, \max }$ and $\phi_{i, \min }$ are the maximum and the minimum values of the $i^{\text {th }}$ objective function, respectively. Eq. (4) escapes potential problems when the magnitudes of the objective functions are quite different. 


\subsubsection{Stopping criterion}

When the maximum number of generations is exceeded or the stall generation is reached, the multi-objective GA is terminated. The stall generation means that the algorithm deals with the specified number of generations with no improvement in the Pareto-set filter.

\subsubsection{Flowchart of improved multi-objective GA}

Fig. 21 shows the flowchart of the improved GA. In Fig. 21, " $n g$ " represents the number of generations.

\subsection{Optimal model of damper system for 3-D building structure}

\subsubsection{Equation of motion for 3-D damped building}

An $n$-story 3-D shear-type building model is shown in Fig. 6 . The dimensions of the building along the $x$ - and $y$-direction are $l$ and $w$, respectively. The center of resistance (CR) of the building does not coincide with the center of mass (CM), but for convenience, it is assumed that each center lies on a single vertical axis, with the eccentricities, $e_{\mathrm{x}}$ and $e_{\mathrm{y}}$, in the $x$ - and $y$-direction respectively. $r_{\mathrm{x}}$ and $r_{\mathrm{y}}$ are the distances from the $\mathrm{CM}$ to the frame columns 4 and 1 , respectively. The mass and moment of inertia of each storey, $m_{i}$ and $\boldsymbol{t}_{i}$, are assumed to be concentrated at each floor level, thus the building model can be idealized to have three degrees of freedom at each floor, i.e. two orthogonal lateral drifts with respect to the ground, $u_{\mathrm{x} i}$ and $u_{\mathrm{y} i}$, and a rotation with respect to a vertical axis. $u_{\theta i} . k_{\mathrm{x} i}, k_{\mathrm{y} i}$ and $k_{\theta i}$ are the resultant stiffness of the building in $x-, y-$, and $\theta$-direction, respectively. Ground accelerations applied in $x$ - and $y$-direction are denoted by the terms $\ddot{u}_{\mathrm{xg}}$ and $\ddot{u}_{\mathrm{yg}}$, while the torsional component is regarded as zero. Dampers may be arranged on the outer frames and provide the control forces $f_{1 i}, f_{2 i}, f_{3 i}$ and $f_{4 i}$ on the corresponding frames. In the definitions of the above variables, the subscript $i$ denotes the $i$ th floor.

The equation of motion for this idealized torsionally coupled n-story building with added dampers can be expressed as, 


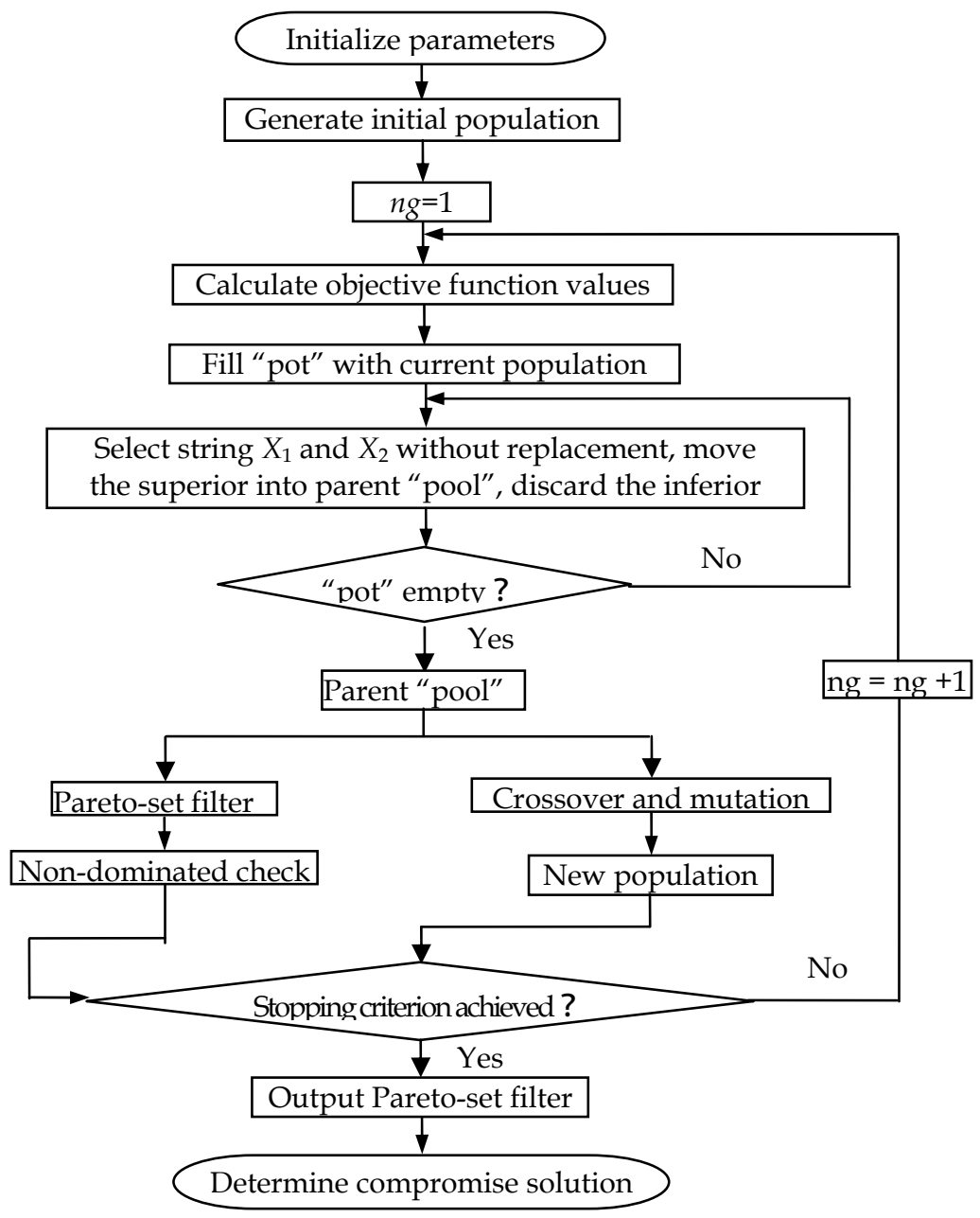

Fig. 21. Flowchart of improved constrained multi-objective GA

$$
M_{\mathrm{s}} \ddot{U}(t)+C_{\mathrm{s}} \dot{U}(t)+K_{\mathrm{s}} U(t)=-M_{\mathrm{s}} D \ddot{U}_{\mathrm{g}}(t)+H F(t)
$$

where $U(t)=\left\{u_{\mathrm{x} 1}(t), u_{\mathrm{x} 2}(t), \cdots, u_{\mathrm{x} n}(t), u_{\mathrm{y} 1}(t), u_{\mathrm{y} 2}(t), \cdots, u_{\mathrm{y} n}(t), u_{\theta 1}(t), u_{\theta 2}(t), \cdots, u_{\theta n}(t)\right\}_{\mathrm{T}}^{\mathrm{T}}$ is the drift vector of the building with respect to the ground, $\ddot{U}_{\mathrm{g}}(t)=\left\{\ddot{u}_{\mathrm{xg}}(t), \ddot{u}_{\mathrm{yg}}(t)\right\}$ denotes the earthquake induced ground acceleration vector, $D=\left[\begin{array}{llllllll}I & \mathbf{0} & ; & \mathbf{0} & I & ; & \mathbf{0} & \mathbf{0}\end{array}\right]$ represents the influencing coefficient matrix, $I$ and $\mathbf{0}$ imply the $n$-column vectors with the elements 1 and zero, and $M_{\mathrm{s}}, K_{\mathrm{s}}$ and $C_{\mathrm{s}}$ mean the mass, stiffness and Rayleigh damping matrices, respectively, given by, 


$$
M_{\mathrm{s}}=\operatorname{diag}\left(M_{\mathrm{x}}, M_{\mathrm{y}}, M_{\theta}\right)
$$

in which $M_{\mathrm{x}}=M_{\mathrm{y}}=\operatorname{diag}\left(m_{1}, m_{2}, \cdots, m_{n}\right), M_{\theta}=\operatorname{diag}\left(\iota_{1}, l_{2}, \cdots, l_{n}\right)$.

$$
K_{\mathrm{s}}=\left[\begin{array}{ccc}
K_{\mathrm{xx}} & \tilde{\mathbf{0}} & K_{\mathrm{x} \theta} \\
\tilde{\mathbf{0}} & K_{\mathrm{yy}} & K_{\mathrm{yy}} e_{\mathrm{x}} \\
K_{\theta \mathrm{x}} & K_{\mathrm{yy}} e_{\mathrm{x}} & K_{\theta \theta}
\end{array}\right]
$$

in which $K_{\mathrm{x} \theta}=\left(K_{\theta \mathrm{x}}\right)^{\mathrm{T}}=-K_{\mathrm{xx}} e_{\mathrm{y}}, K_{\mathrm{y} \theta}=\left(K_{\theta \mathrm{y}}\right)^{\mathrm{T}}=K_{\mathrm{yy}} e_{\mathrm{x}}$, and

$$
K_{\mathrm{xx}}=\left[\begin{array}{ccccc}
k_{\mathrm{x} 1}+k_{\mathrm{x} 2} & -k_{\mathrm{x} 2} & 0 & \cdots & 0 \\
-k_{\mathrm{x} 2} & k_{\mathrm{x} 2}+k_{\mathrm{x} 3} & -k_{\mathrm{x} 3} & \ddots & \vdots \\
0 & \ddots & \ddots & \ddots & 0 \\
\vdots & \ddots & -k_{\mathrm{x} n-1} & k_{\mathrm{x} n-1}+k_{\mathrm{x} n} & -k_{\mathrm{x} n} \\
0 & \cdots & 0 & -k_{\mathrm{x} n} & k_{\mathrm{x} n}
\end{array}\right],
$$

where $\tilde{\mathbf{0}}$ means the $n \times n$ zero matrix, and the elements in $K_{\mathrm{yy}}$ and $K_{\theta \theta}$ are similar to those in $K_{\mathrm{xx}}$ except that the subscripts yy or $\theta \theta$ are substitutes for $\mathrm{xx}$. $F(t)=\left\{f_{11}(t), f_{21}(t), f_{31}(t), f_{41}(t), f_{12}(t), f_{22}(t), f_{32}(t), f_{42}(t), \cdots, f_{1 n}(t), f_{2 n}(t), f_{3 n}(t), f_{4 n}(t)\right\}^{\mathrm{T}}$ represents the control force vector of the dampers; if no dampers are installed on the $j^{\text {th }}$ frame at the $i^{\text {th }}$ floor, $f_{j i}(t)=0 . H$ is the matrix specifying the locations of the control forces; if $F(t)_{i}=\left\{f_{1 i}(t), f_{2 i}(t), f_{3 i}(t), f_{4 i}(t)\right\}^{\mathrm{T}} \quad$ and $\quad F_{i+1}(t)=\left\{f_{1(i+1)}(t), f_{2(i+1)}(t), f_{3(i+1)}(t) n\right.$, $\left.f_{4(i+1)}(t)\right\}^{\mathrm{T}}$ are the control forces of the dampers on the $i^{\text {th }}$ floor and $(i+1)^{\text {th }}$ floor respectively, and their corresponding location matrices are $H_{i}$ and $H_{i+1}$, then the resultant control force for the $i$ th floor in $x-, y-$, and $\theta$-direction is written as $H_{i} \times F_{i}(t)-H_{i+1} \times F_{i+1}(t)$, in which

$$
H_{i}=\left[\begin{array}{cccc}
-1 & 0 & -1 & 0 \\
0 & -1 & 0 & -1 \\
r_{\mathrm{y}} & l-r_{\mathrm{x}} & r_{\mathrm{y}}-w & -r_{\mathrm{x}}
\end{array}\right],(i=1,2, \cdots, n)
$$

$H$ is derived from integrating $H_{i}$. 
Due to the translation-torsion coupling effects, the corners of the floors generally suffer maximum drifts. These drifts can be computed according to the CM's drifts and the coordinates of the corners relative to the CM.

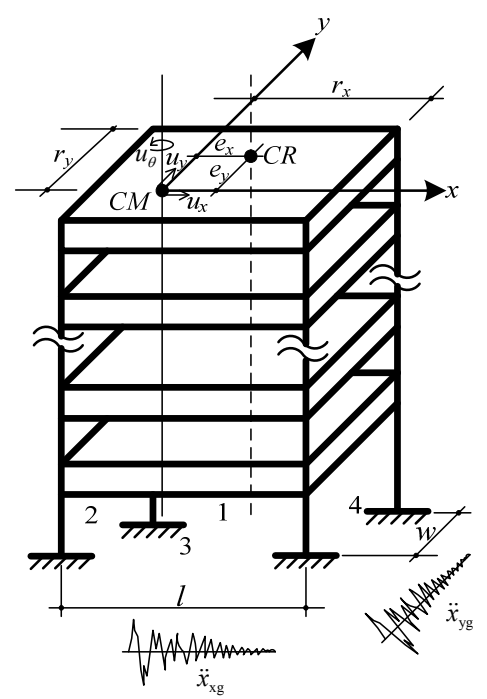

Fig. 22. Schematic representation of 3-D building

\subsubsection{Optimal model of 3-D damped building}

Given a damper with pre-determined mechanical properties, it is of interest to determine the size and position of such devices in a structure to maximize their effectiveness at minimum cost. This problem is presented in following multi-objective mathematical form.

In this MOP, the design variables are the size and position of dampers. Objectives are to minimize (1) the total size of the dampers to be placed in the structure, (2) the peak relative interstory drift, and (3) the peak relative torsion. These three objective functions $\phi_{1}, \phi_{2}$ and $\phi_{3}$ are given by

$$
\begin{gathered}
\phi_{1}=\sum_{i=1}^{n} \sum_{j=1}^{4} n_{d(i j)}, \\
\phi_{2}=\max _{i}\left(\frac{\left|u_{x(i)}^{f}-u_{x(i-1)}^{f}\right|_{\max }}{h}, \frac{\left|u_{y(i)}^{f}-u_{y(i-1)}^{f}\right|_{\max }}{h}\right),
\end{gathered}
$$




$$
\phi_{3}=\max _{i}\left(\frac{\left|u_{x(i)}^{f}\right|_{\max }}{\left|u_{x(i)}^{f}\right|_{\text {mean }}}, \frac{\left|u_{y(i)}^{f}\right|_{\max }}{\left|u_{y(i)}^{f}\right|_{\text {mean }}}, \frac{\left|u_{x(i)}^{f}-u_{x(i-1)}^{f}\right|_{\max }}{\left|u_{x(i)}^{f}-u_{x(i-1)}^{f}\right|_{\text {mean }}}, \frac{\left|u_{y(i)}^{f}-u_{y(i-1)}^{f}\right|_{\max }}{\left|u_{y(i)}^{f}-u_{y(i-1)}^{f}\right|_{\text {mean }}}\right),
$$

where $n_{d(i j)}$ means the size of dampers on the $j^{\text {th }}$ frame at the $i^{\text {th }}$ floor, $\left|u_{x(i)}^{f}\right|_{\max }$ and $\left|u_{y(i)}^{f}\right|_{\max }$ imply the max drift of the $i^{\text {th }}$ floor with respect to the ground in $x$ - and $y$-direction, $\left|u_{x(i)}^{f}\right|_{\text {mean }}$ and $\left|u_{y(i)}^{f}\right|_{\text {mean }}$ denote the mean value of the maximum and minimum drift of the $i^{\text {th }}$ floor with respect to the ground in $x$ - and $y$-direction, $\left|u_{x(i)}^{f}-u_{x(i-1)}^{f}\right|_{\max }$ and $\left|u_{y(i)}^{f}-u_{y(i-1)}^{f}\right|_{\max }$ represent the max interstory drift of the $i^{\text {th }}$ floor in $x$ - and $y$-direction, $\left|u_{x(i)}^{f}-u_{x(i-1)}^{f}\right|_{\text {mean }}$ and $\left|u_{y(i)}^{f}-u_{y(i-1)}^{f}\right|_{\text {mean }}$ express the mean value of the maximum and minimum interstory drift of the $i^{\text {th }}$ floor in $x$ - and $y$-direction, respectively, and $h$ renders story height. For the three objectives, the first one is used to evaluate the reliability and economy of the damper system, and the others are adopted to quantify the safety of the building.

The constraints for the peak relative interstory drift and the peak relative torsion are formulated by,

$$
\begin{aligned}
& g_{1}=\phi_{2}-[\theta] \leq 0, \\
& g_{2}=\phi_{3}-[R] \leq 0,
\end{aligned}
$$

in which $[\theta]$ is the allowable relative interstory drift, and $[R]$ means the allowable relative torsion.

\subsection{Numerical Example}

\subsubsection{Example frame and dampers}

The dimensions of the building along the $\mathrm{x}$ - and $\mathrm{y}$-directions are $46 \mathrm{~m}$ and $26 \mathrm{~m}$, respectively. Story height is $3.3 \mathrm{~m}$, and eccentricities $e_{x}=5 \mathrm{~m}$ and $e_{y}=2 \mathrm{~m}$. The building is assumed to be with the Rayleigh damped, with damping ratios $5 \%$ for the first two modes. Other parameters are given in Table 5.

Ren and Li (2008) developed a SMA damper with inherent self-centering behavior and enhanced energy dissipation capacity. The SMA wires have a diameter of $0.8 \mathrm{~mm}$ with a maximum allowable strain of about $6 \%$. One-third of the wires are pre-tensioned to a strain level of $3 \%$ while the remaining two-thirds are not pre-tensioned. The lengths of the 
pre-tensioned and relaxed wires are $0.385 \mathrm{~m}$ and $0.77 \mathrm{~m}$, respectively, which is chosen such that the strain of the wires at a 0.007 relative interstory drift is kept below $6 \%$. Here, the allowable value for the relative interstory drift is taken as 0.007 to ensure that no structural damage appears and the main structure functions in an approximately elastic state. In addition, given that the amount of pre-tensioned and relaxed wires in the unit damper are 4 and 2, respectively, so the size of the dampers is defined as the ratio of the practical amount of the wires to the amount of the wires in the unit damper. The mechanical parameters of the SMA wires refer to Refs. (Ren et al. 2007a; 2007b).

Table 5. Parameters for example building

\begin{tabular}{|c|c|c|c|c|c|}
\hline \multirow[b]{2}{*}{ Floor } & \multirow{2}{*}{$\begin{array}{l}\text { Mass } \\
(\mathrm{kg})\end{array}$} & \multirow{2}{*}{$\begin{array}{l}\text { Moment of } \\
\text { inertia } \\
\left(\mathrm{kg} \cdot \mathrm{m}^{2}\right)\end{array}$} & \multicolumn{3}{|c|}{ Stiffness } \\
\hline & & & $k_{x}(\mathrm{~N} / \mathrm{m})$ & $k_{y}(\mathrm{~N} / \mathrm{m})$ & $k_{\theta}(\mathrm{N} \cdot \mathrm{m} / \mathrm{rad})$ \\
\hline 1 & 18375 & $8.337 \times 10^{6}$ & $3.080 \times 10^{7}$ & $3.080 \times 10^{7}$ & $1.308 \times 10^{10}$ \\
\hline 2 & 16118 & $7.098 \times 10^{6}$ & $2.643 \times 10^{7}$ & $2.643 \times 10^{7}$ & $1.063 \times 10^{10}$ \\
\hline 3 & 16118 & $7.098 \times 10^{6}$ & $2.643 \times 10^{7}$ & $2.643 \times 10^{7}$ & $1.063 \times 10^{10}$ \\
\hline 4 & 16118 & $7.098 \times 10^{6}$ & $2.643 \times 10^{7}$ & $2.643 \times 10^{7}$ & $1.063 \times 10^{10}$ \\
\hline 5 & 16118 & $7.098 \times 10^{6}$ & $2.643 \times 10^{7}$ & $2.643 \times 10^{7}$ & $1.063 \times 10^{10}$ \\
\hline 6 & 16118 & $7.098 \times 10^{6}$ & $2.643 \times 10^{7}$ & $2.643 \times 10^{7}$ & $1.063 \times 10^{10}$ \\
\hline
\end{tabular}

The Morgan Hill earthquake, which was recorded at Coyote Lake Dam in the Morgan Hill, CA, USA, during April 24, 1984, is applied to the structure. The ground peak acceleration in the $x$-direction is scaled to $3.0 \mathrm{~m} / \mathrm{s}^{2}$, and the peak acceleration in the $\mathrm{y}$-direction is scaled to $2.55 \mathrm{~m} / \mathrm{s}^{2}$.

The responses of the bare structure are shown in Fig. 23. The maximum responses are seen on the 2 nd floor, i.e. the peak relative interstory drift is 0.0067 , and the peak relative torsion is about 1.51 . Thus, in the MOP, the allowable relative interstory drift is considered to be 0.0067 and the relative torsion cannot exceed 1.4 according to Chinese Code for Seismic Design of Buildings (GB 50011-2001).

\subsubsection{Parameters of GA}

The improved GA encodes the design variables into a binary-alphabet chromosome. For the six-story asymmetrical building, the dampers can be installed at 24 different positions. In each position, the maximum size of the dampers is taken as 15 , whereas the minimum is 0 . Given a resolution between each value of 1 being desired, the chromosome string length is 96 bits. The population size is selected as 20. The probability of crossover and mutation are chosen as 0.7 and 0.0073 , respectively. The GA is allowed to run 200 generations and the stall generation is taken to be 20 . 
4.4.3 Numerical results
The collected set of 80 non-dominated designs is shown in Fig. 24. It is observed that $\theta_{\max }$ varies between 0.0049 and 0.0061 and $R_{\max }$ varies between 1.27 and 1.4, which indicates that the algorithm can effectively control the coupled lateral-torsional responses of the building. Moreover, the trend denotes that the performance in terms of one objective can be improved at the cost of the poorer performances of other objectives, i.e. decreasing the size of the dampers results in the increased responses of the building.

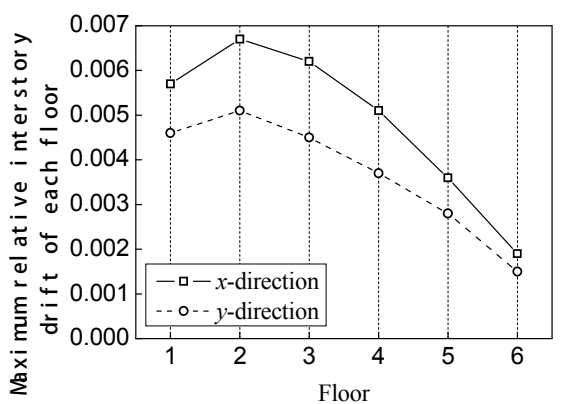

(a)

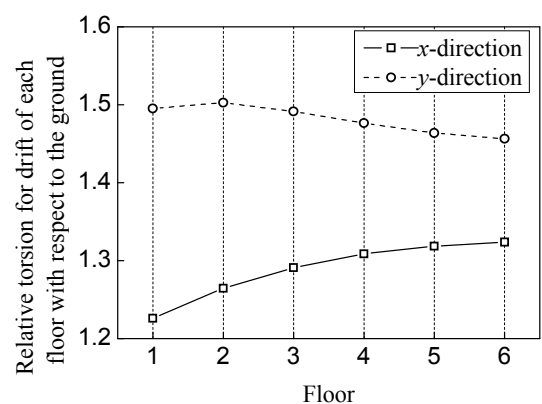

(b)

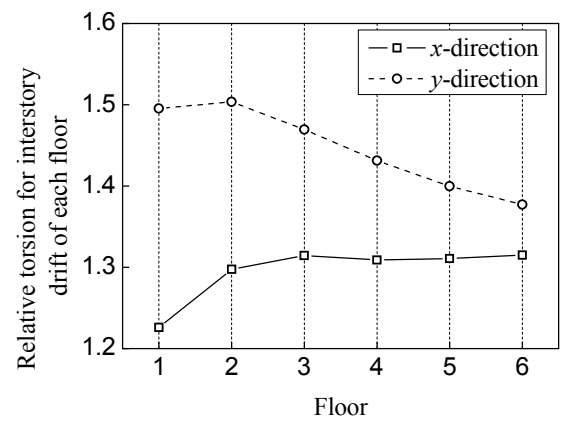

(c)

Fig. 23. Peak responses of 3-D bare structure subjected to earthquake 


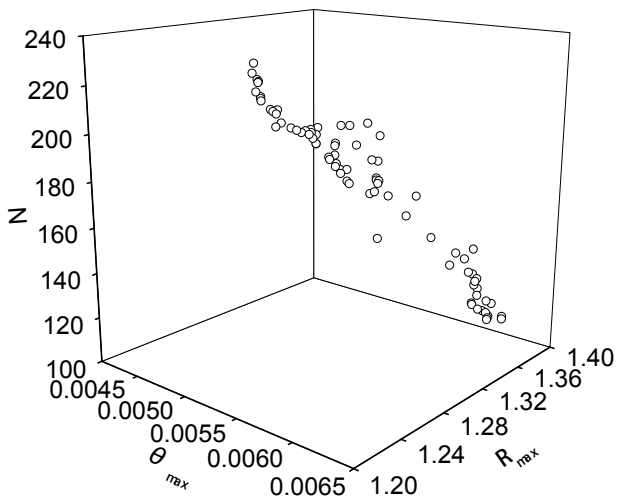

Fig. 24. Non-dominated individuals for 3-D building with SMA dampers

The non-dominated designs take information on the size and position of the dampers. Table 6 optionally lists ten optima. Taking case (1) for example, the dampers with different sizes are installed on frames 1, 2, 3 and 4 at each floor: 5, 2, 12 and 2 dampers on the $1^{\text {st }}$ floor, 6, 1, 9 and 1 dampers on the $2^{\text {nd }}$ floor, $1,0,13$ and 1 dampers on the $3^{\text {rd }}$ floor, 3, 10, 15 and 5 dampers on the $4^{\text {th }}$ floor, $1,1,8$ and 8 dampers on the $5^{\text {th }}$ floor, and $1,4,0$ and 0 dampers on the $6^{\text {th }}$ floor.

Table 6. Distribution of dampers and structural responses

\begin{tabular}{|c|c|c|}
\hline $\begin{array}{c}\text { Cas } \\
\mathrm{e}\end{array}$ & Distribution of dampers & {$\left[N, \theta_{\max }, R_{\max }\right]$} \\
\hline (1) & 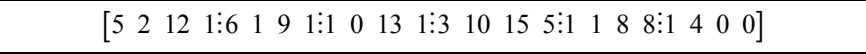 & {$[108,0.00609,1.3965]$} \\
\hline (2) & {$\left[\begin{array}{lllllllllllllllllll}15 & 0 & 11 & 0: 6 & 1 & 9 & 1: 1 & 1 & 13 & 1 \vdots 3 & 10 & 15 & 5: 1 & 1 & 8 & 4 \vdots 4 & 5 & 1 & 0\end{array}\right]$} & {$[116,0.00598,1.3916]$} \\
\hline (3) & {$\left[\begin{array}{lllllllllllllllllll}6 & 2 & 12 & 1: 10 & 1 & 10 & 1: 1 & 0 & 14 & 1: 3 & 10 & 15 & 1 \vdots 2 & 10 & 15 & 4: 4 & 5 & 0 & 9\end{array}\right]$} & {$[137,0.00586,1.3793]$} \\
\hline (4) & {$\left[\begin{array}{lllllllllllllllllll}14 & 0 & 15 & 0 \vdots 15 & 8 & 15 & 0 \vdots 1 & 7 & 13 & 1 \vdots 3 & 10 & 15 & 2 \vdots 1 & 6 & 8 & 7 \vdots 1 & 4 & 1 & 0\end{array}\right]$} & {$[147,0.00536,1.3412]$} \\
\hline (5) & {$\left[\begin{array}{lllllllllllllllllll}15 & 3 & 15 & 0: 15 & 15 & 15 & 0: 14 & 1 & 13 & 1: 3 & 10 & 15 & 5: 1 & 1 & 8 & 4: 4 & 5 & 1 & 0\end{array}\right]$} & {$[164,0.00516,1.3535]$} \\
\hline (6) & 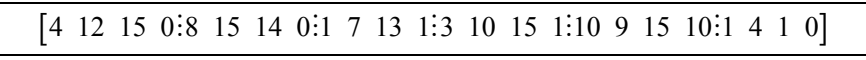 & {$[169,0.00550,1.3362]$} \\
\hline (7) & {$\left[\begin{array}{lllllllllllllllllll}8 & 15 & 15 & 0: 15 & 13 & 15 & 0: 14 & 13 & 14 & 0: 12 & 12 & 15 & 1: 2 & 13 & 0 & 3 \vdots 4 & 5 & 1 & 0\end{array}\right]$} & {$[190,0.00499,1.3168]$} \\
\hline 8 & {$\left[\begin{array}{lllllllllllllllllll}15 & 15 & 15 & 0: 15 & 15 & 15 & 0: 14 & 13 & 14 & 1: 12 & 12 & 15 & 1: 2 & 13 & 0 & 8: 1 & 11 & 0 & 0\end{array}\right]$} & {$[207,0.00490,1.2897]$} \\
\hline (9) & 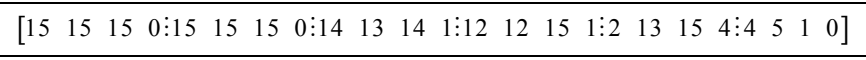 & {$[216,0.00487,1.2736]$} \\
\hline$(10$ & 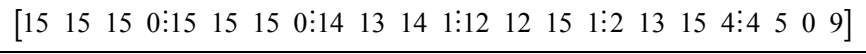 & {$[224,0.00488,1.2703]$} \\
\hline
\end{tabular}

\section{Conclusions}

(1) The properties of the superelastic SMA reinforced concrete members and structures are studied. The following conclusions can be drawn:

- Superelastic SMA reinforced concrete beams have good self-rehabilitation capabilities; 
- Superelastic SMAs can be used as an inner energy dissipation device to change the dynamic properties of the concrete members or structures;

- Superelastic SMA reinforced structures have less horizontal and torsional responses and good self-recentering capabilities compared to reinforced concrete structures without SMAs.

(2) To assess the effectiveness of an innovative energy dissipation system (HSMAFD) in reducing the seismic response of structures, shaking table tests on a 1/4-scale, 3-story steel frame building with were carried out. The comparisons of dynamic behaviors, i.e. storey displacements, interstorey drifts and storey accelerations, of structural model with and without HSMAFD under various seismic loading were conducted.

- The fundamental frequency of the structure increases by about $50 \%$ after HSMAFD was installed due to its supplemental stiffness.

- The interstorey drifts and the absolute displacements relative to the table of the building have been non-identically reduced by HSMAFD. The first floor has a more significant effect than the other two floors because the arrangement of the HSMAFD in the first floor.

- The results show that HSMAFD were effective in suppressing the dynamic response of building structures subjected to different earthquakes by dissipating a large portion of energy through their hysteretic loops.

(3) A MOP concerning the optimal size and position of dampers in 3-D structures to minimize the translation-torsion coupling effects at minimum cost is given.

- An improved constrained multi-objective GA is developed. Based on the two-branch tournament GA, and an improved selection operator is constructed by evaluating individuals according to their non-dominance in one run, which guarantees the better performing individual winning its competition and less computational effort taken. For a constrained problem, the Pareto-based penalty function method is advanced, containing information on an individual status (feasible or infeasible), position in a search space, and distance from a Pareto optimal set, essential for success in seeking optima. The improved GA is followed by verification through two mathematical benchmark problems.

- The optimal distribution of the SMA dampers for a six-storey 3-D building subjected to earthquake is carried out. The size and position of the dampers are chosen as the design variables. The total size of dampers, the peak relative interstory drift, and the peak relative torsion are considered as the objective functions to evaluate the economy and safety of the constructed facilities. Numerical results generate a set of non-dominated solutions. Thus a suitable design can be chosen to meet the desired performance requirements. 


\section{References}

Agrawal, A. K. \& Yang, J. N. (2000). Optimal placement of passive dampers on seismic and wind-excited buildings using combinatorial optimization. Journal of Intelligent Material Systems and Structure, 10(12), 997-1014.

Ahlawat, A. S. \& Ramaswamy, A., (2003). Multi-objective optimal absorber system for torsionally coupled seismically excited structures. Engineering Structures, 25(7), 941-950.

Cheng, F. Y. \& Li, D. (1997). Multi-objective optimization design with pareto genetic algorithm," Journal of Structural Engineering, 123(9), 1252-1261.

Choi, E., Nam, T. H. \& Cho, S. C. et al. (2008). The behavior of concrete cylinders confined by shape memory alloy wires. Smart Materials and Structures, 17, 1-10.

Crossley, W. A., Cook, A. M. \& Fanjoy, D. W.et al. (1999). Using the two-branch tournament genetic algorithm for multi-objective design. AIAA Journal, 37(2), 261-267.

Cui, D., Li, H. N. \& Song, G. B. (2009). Experimental investigation on dynamic properties of concrete columns embedded with shape memory alloy. Active and Passive Smart Structures and Integrated Systems; Proc. SPIE 7292, 729248.

Dolce, M., Cardone, D. \& Marnetto, R. (2000). Implementation and testing of passive control devices based on shape memory alloys. Earthquake Engineering and Structural Dynamics, 29, 945-968.

Huang J Z, Wang Z \& Ma R L. (2007). Multiobjective optimization design of aseismic steel frames using genetic algorithm. Chinese Journal of Theoretical and Applied Mechanics, 39(3), 389-397.

Li H. N., Qian H. \& Song G. B. (2008). Experimental and Analytical Investigation on Innovative Compound Shape Memory Alloys Dampers for Structure Control. Proceedings of SPIE: Smart Structures and materials \& Nondestructive Evaluation and health Monitoring. March, San Diego, California, USA.

Li, H. N., Cui, D. \& Song, G. B. (2006). Experimental investigation on self-rehabilitation of intelligent concrete beams reinforced with shape memory alloys. Proceedings of the Tenth Biennial ASCE Aerospace Division International Conference on Engineering, Construction, and Operations in Challenging Environments (Earth and Space 2006), March, Houston, USA.

Li, Q. S., Liu, D. K. \& Zhang, N. et al. (2001). Multi-level design model and genetic algorithm for structural control system optimization. Earthquake Engineering and Structural Dynamics, 30, 927-942.

Maji, A. K. \& Negret, I. (1998). Smart prestressing with shape-memory alloy. Journal of Engineering Mechanics, 124 (10), 1121-1128.

Ren, W. J., Li, H. N. \& Song, G. B. (2007) A one-dimensional strain-rate dependent constitutive model for superelastic shape memory alloys. Smart Materials and Structures, 16, 191-197.

Ren, W. J., Li, H. N. \& Song, G. B. (2008) Experimental investigation and numerical evaluation of an innovative shape memory alloy damper. Active and Passive Smart Structures and Integrated Systems; Proc. SPIE 6928 69280W.

Ren, W. J., Li, H. N. \& Song, G. B., (2007). Phenomenological modeling of the cyclic behavior of superelastic shape memory alloys. Smart Materials and Structures, 16, 1083-1089.

Shukla, A. K. \& Datta, T. K. (1999). Optimal use of viscoelastic dampers in building frames for seismic force. Journal of Structural Engineering, 125(4), 401-409. 
Singh, M. P. \& Moreschi, L. M. (2002). Optimal placement of dampers for passive response control. Earthquake Engineering and Structural Dynamics, 31(4), 955-976.

Song, G., Mo, Y. L. \&Otero, K. et al. (2006). Health monitoring and rehabilitation of a concrete structure using intelligent materials. Smart Materials and Structures, 15, 309-314.

Takewaki, I. (1997). Optimal damper placement for minimum transfer functions. Earthquake Engineering and Structural Dynamics, 26(11), 1113-1124.

Wongprasert, N. and Symans, M. D. (2004). Application of a genetic algorithm for optimal damper distribution within the nonlinear seismic benchmark building. Journal of Engineering Mechanics, 130(4), 401-406.

Wu, B., Ou, J. P. \& Soong, T. T. (1997). Optimal placement of energy dissipation devices for three-dimensional structures. Engineering Structures, 19(2), 113-125.

Zhang, R. H. \& Soong, T. T. (1992). Seismic design of viscoelastic dampers for structural applications. Journal of Structural Engineering, 118(5), 1375-1392.

Zheng, D. X. M., Ng, S. T. \& Kumaraswamy, M. M. (2004). Applying a genetic algorithm-based multiobjective approach for time-cost optimization. Journal of Construction Engineering and Management, 130(2), 168-176. 


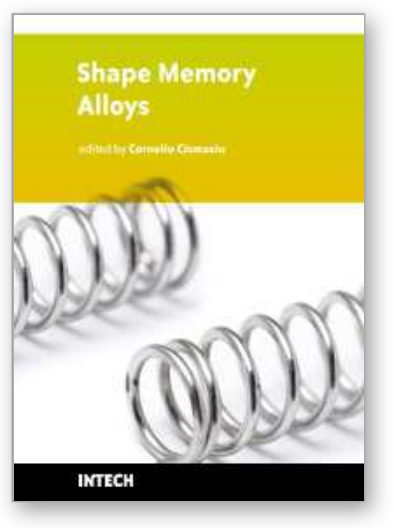

\author{
Shape Memory Alloys \\ Edited by Corneliu Cismasiu
}

ISBN 978-953-307-106-0

Hard cover, 210 pages

Publisher Sciyo

Published online 18, October, 2010

Published in print edition October, 2010

In the last decades, the Shape Memory Alloys, with their peculiar thermo-mechanical properties, high corrosion and extraordinary fatigue resistance, have become more popular in research and engineering applications. This book contains a number of relevant international contributions related to their properties, constitutive models and numerical simulation, medical and civil engineering applications, as well as aspects related to their processing.

\title{
How to reference
}

In order to correctly reference this scholarly work, feel free to copy and paste the following:

Hongnan Li and Hui Qian (2010). Seismic Vibration Control of Structures Using Superelastic Shape Memory Alloys, Shape Memory Alloys, Corneliu Cismasiu (Ed.), ISBN: 978-953-307-106-0, InTech, Available from: http://www.intechopen.com/books/shape-memory-alloys/seismic-vibration-control-of-structures-usingsuperelastic-shape-memory-alloys

\section{INTECH}

open science | open minds

\section{InTech Europe}

University Campus STeP Ri

Slavka Krautzeka 83/A

51000 Rijeka, Croatia

Phone: +385 (51) 770447

Fax: +385 (51) 686166

www.intechopen.com

\section{InTech China}

Unit 405, Office Block, Hotel Equatorial Shanghai

No.65, Yan An Road (West), Shanghai, 200040, China 中国上海市延安西路65号上海国际贵都大饭店办公楼405单元

Phone: +86-21-62489820

Fax: +86-21-62489821 
(C) 2010 The Author(s). Licensee IntechOpen. This chapter is distributed under the terms of the Creative Commons Attribution-NonCommercialShareAlike-3.0 License, which permits use, distribution and reproduction for non-commercial purposes, provided the original is properly cited and derivative works building on this content are distributed under the same license. 